\title{
Endoscopic ultrasound-guided salvage for a disconnected choledochojejunostomy anastomosis through a jejunal stoma
}

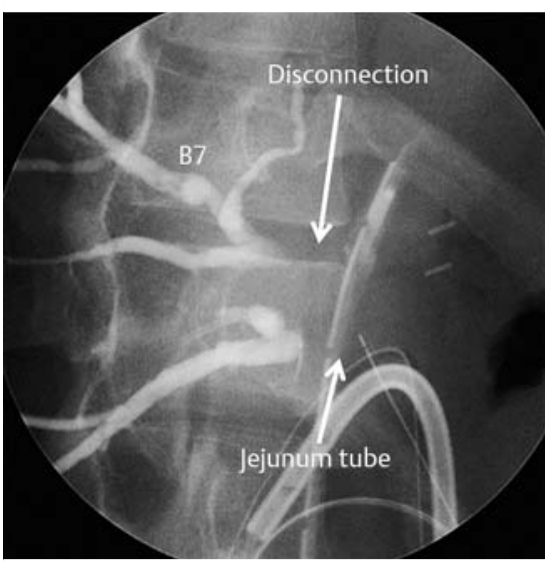

> Fig. 1 Fluoroscopic image suggesting a complete disconnection between the jejunum and the bile duct at segment 7 (arrows) in a patient with a history of Roux-en-Y choledochojejunostomy.

A 25-year-old man with a history of deceased-donor liver transplantation using a right lobe graft with Roux-en-Y choledochojejunostomy was referred for endoscopic management of cholangitis due to anastomotic strictures [1] ( Fig. 1). The patient developed postoperative bile leakage and disconnection of the choledochojejunostomy anastomosis. He underwent percutaneous transhepatic placement of catheters for the bile ducts in segments 5,6 , and 7 (B5-7). Re-canalization was achieved by percutaneous procedures for $\mathrm{B} 5$ and $\mathrm{B} 6$, whereas a complete disconnection between B7 and the jejunum was not amenable to the percutaneous approach or doubleballoon endoscopy. Therefore, we decided to perform endoscopic ultrasound (EUS)-guided drainage to re-anastomose B7 with the jejunum.

We inserted an echoendoscope (EG580UT; Fujifilm Corp., Tokyo, Japan) through a pre-existing jejunal stoma, after dilating the fistula with a $20-\mathrm{mm}$ balloon catheter. With the help of contrast injection through the biliary catheter, B7 was punctured using a 19-gauge
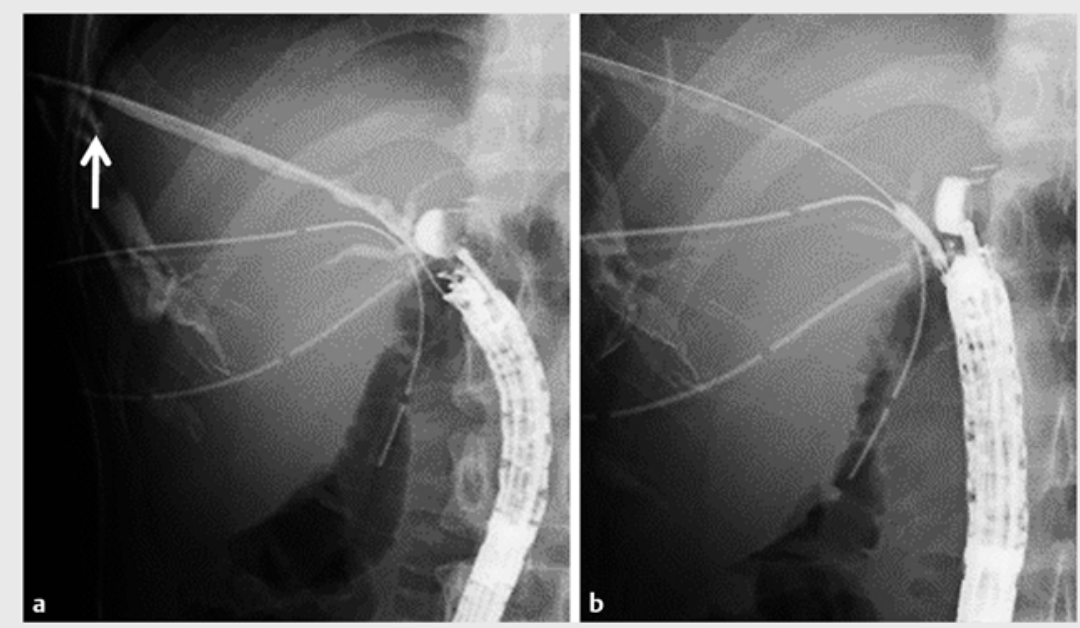

Fig. 2 Radiographic images during endoscopic ultrasound-guided biliary drainage showing: a a guidewire passed through the fistula of a percutaneous catheter; $\mathbf{b}$ balloon dilation of the puncture site.
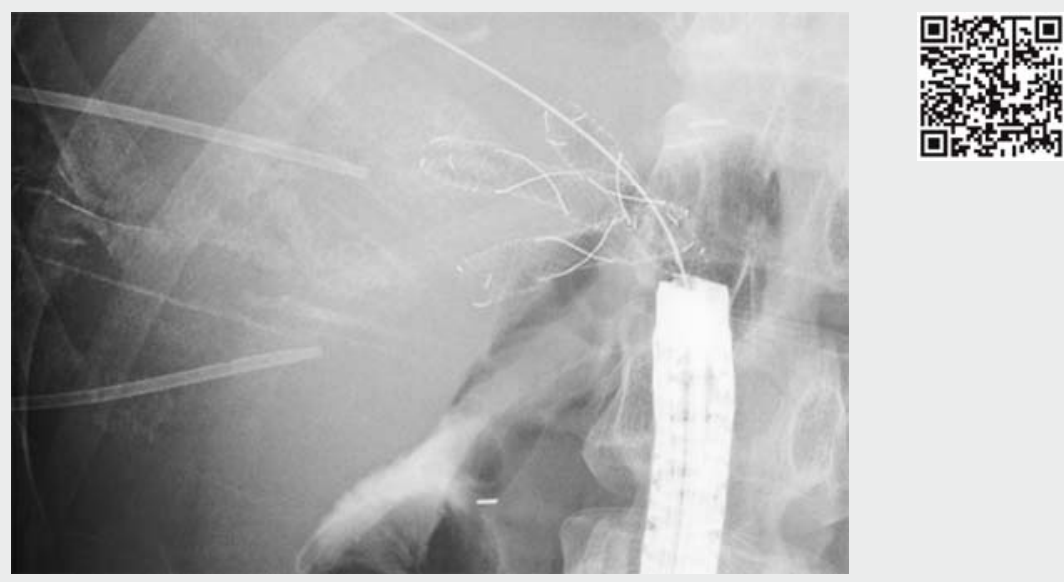

$\nabla$ Video 1 Endoscopic ultrasound-guided choledochojejunostomy for an anastomotic disconnection in a patient with a history of Roux-en-Y choledochojejunostomy. Three self-expandable metal stents are inserted. After their removal 3 months later, the choledochojejunostomy anastomosis is left widely open.

needle and a 0.025-inch guidewire was passed through the fistula of a percutaneous catheter. After inserting a balloon catheter over the guidewire with exter- nal traction, we dilated the puncture site and deployed a 10-Fr percutaneous catheter into the jejunum across B7 ( $\mathbf{F i g . 2}$ ). 


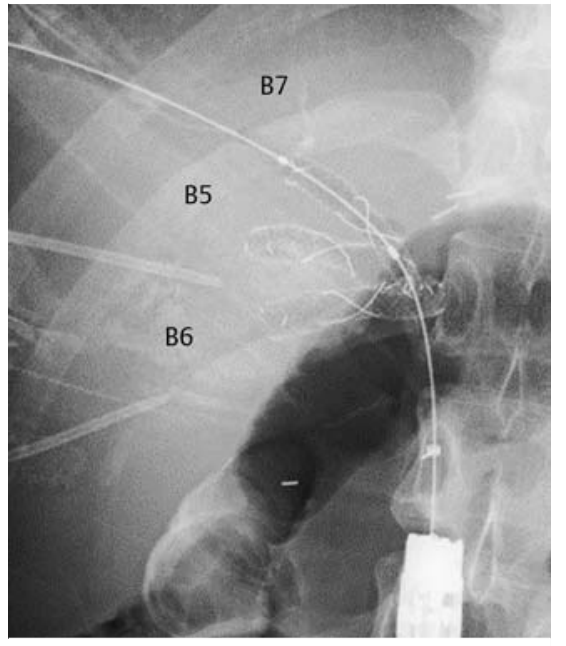

- Fig. 3 Radiographic image showing three fully-covered self-expandable metal stents placed endoscopically into the three biliary branches.

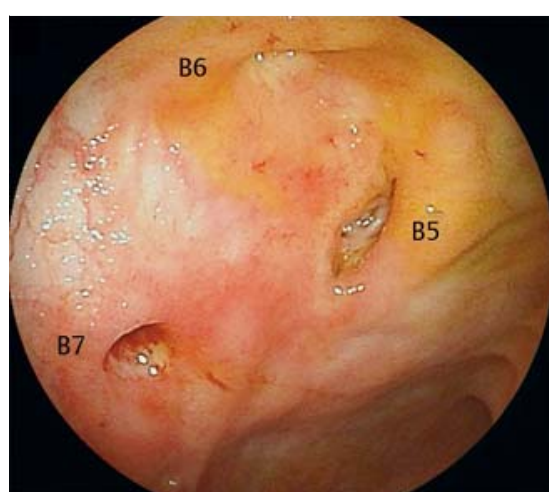

- Fig. 4 Endoscopic image suggesting that the choledochojejunostomy anastomosis was widely open after removal of the self-expandable metal stents.
In the following session, we inserted a forward-viewing endoscope (GIF-2T240; Olympus Medical, Tokyo, Japan) through the stoma and replaced each of the percutaneous catheters with fully-covered self-expandable metal stents $(8 \mathrm{~mm} \times 4 \mathrm{~cm}$; BONASTENT M-Intraductal; Sewoon Medical Co., Ltd., Chungcheongnam-do, South Korea) ( Fig.3) [2]. The metal stents were subsequently removed endoscopically 3 months later, with no recurrence of cholangitis (> Fig. 4).

EUS-guided biliary drainage for a complicated anastomotic disconnection was feasible through a jejunal stoma ( $>$ Video 1 ). Given recent advances in EUS-guided pancreatobiliary interventions $[3,4]$, the use of a jejunal stoma as a port for endoscopic biliary access could further expand this developing frontier of non-surgical management for postoperative complications [5].

Endoscopy_UCTN_Code_TTT_1AR_2AG

\section{Competing interests}

None

The authors

Tatsuya Sato, Yousuke Nakai, Tsuyoshi Hamada, Naminatsu Takahara, Suguru Mizuno, Hirofumi Kogure, Kazuhiko Koike Department of Gastroenterology, Graduate School of Medicine, The University of Tokyo, Tokyo, Japan

\section{Corresponding author}

\section{Yousuke Nakai, MD, PhD}

Department of Gastroenterology, Graduate School of Medicine, The University of Tokyo, 7-3-1 Hongo, Bunkyo-ku, Tokyo 113-8655, Japan

Fax: +81-3-38140021

ynakai-tky@umin.ac.jp

\section{References}

[1] Tsujino $\mathrm{T}$, Isayama $\mathrm{H}$, Kogure $\mathrm{H}$ et al. Endoscopic management of biliary strictures after living donor liver transplantation. Clin J Gastroenterol 2017; 10: 297-311

[2] Moon JH, Choi H], Koo HC et al. Feasibility of placing a modified fully covered self-expandable metal stent above the papilla to minimize stent-induced bile duct injury in patients with refractory benign biliary strictures (with videos). Gastrointest Endosc 2012; 75: 1080- 1085

[3] Nakai $\mathrm{Y}$, Isayama H, Yamamoto $\mathrm{N}$ et al. Indications for endoscopic ultrasonography (EUS)-guided biliary intervention: Does EUS always come after failed endoscopic retrograde cholangiopancreatography? Dig Endosc 2017; 29: 218-225

[4] Teoh AYB, Dhir V, Kida M et al. Consensus guidelines on the optimal management in interventional EUS procedures: results from the Asian EUS group RAND/UCLA expert panel. Gut 2018; 67: 1209-1228

[5] Hu B, Sun B, Cai Q et al. Asia-Pacific consensus guidelines for endoscopic management of benign biliary strictures. Gastrointest Endosc 2017; 86: 44-58

\section{Bibliography}

DOI https://doi.org/10.1055/a-0871-2076

Published online: 1.4.2019

Endoscopy 2019; 51: E172-E173

(c) Georg Thieme Verlag KG

Stuttgart · New York

ISSN 0013-726X

\section{ENDOSCOPY E-VIDEOS \\ https://eref.thieme.de/e-videos}

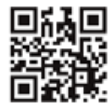

Endoscopy E-Videos is a free access online section, reporting on interesting cases and new

techniques in gastroenterological endoscopy. All papers include a high quality video and all contributions are freely accessible online.

This section has its own submission website at https://mc.manuscriptcentral.com/e-videos 